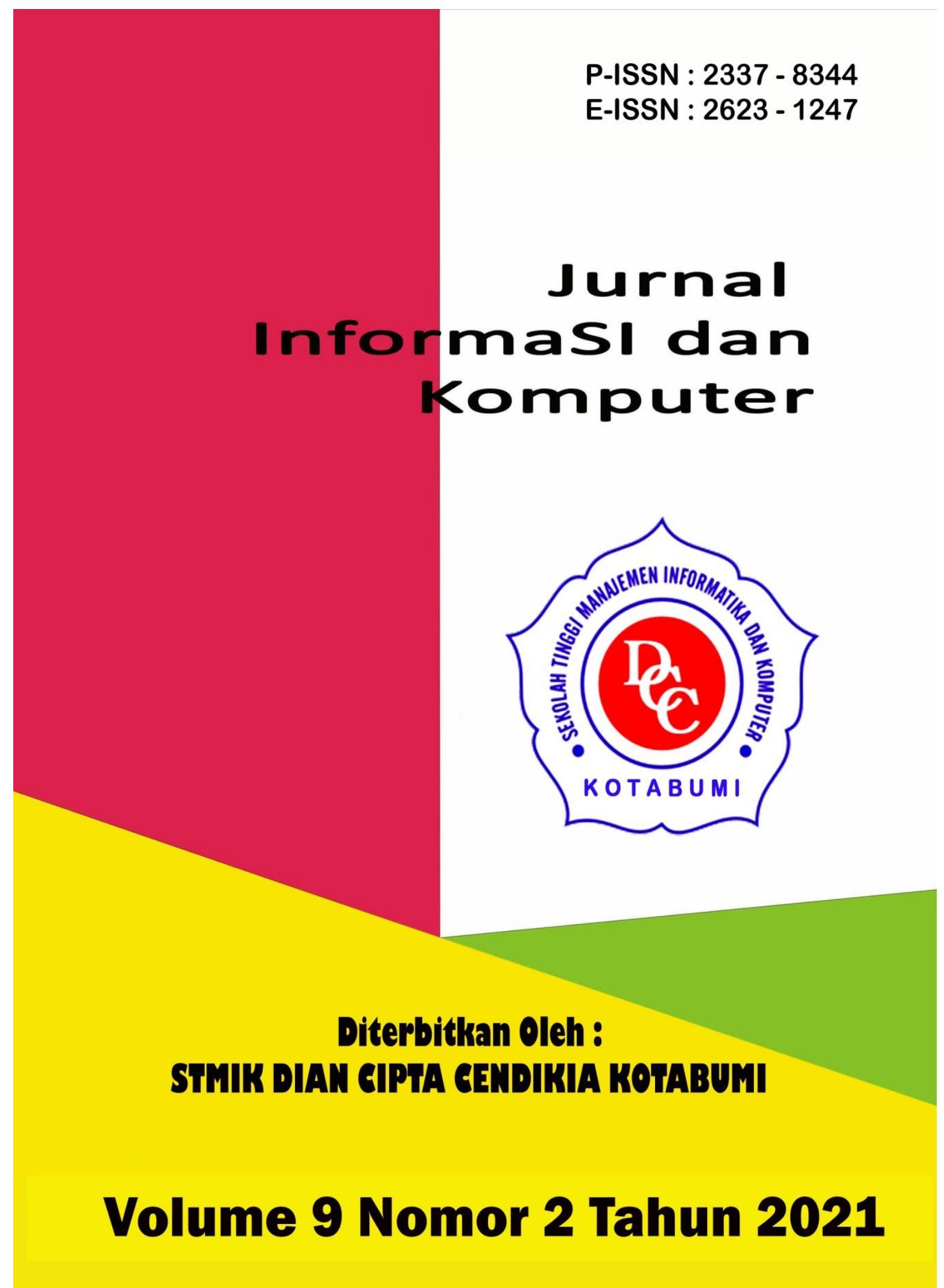




\section{Penerbit}

\section{Lembaga Penelitian STMIK Dian Cipta Cendikia Kotabumi}

Hak atas naskahh/tulisan tetap berada pada penulis, isi diluar tangung jawab penerbit dan Dewan Penyunting 


\section{PENGANTAR REDAKSI}

Puji syukur dipanjatkan kehadirat Tuhan Yang Maha Esa, atas karunia dan limpahan rahmatNYA jualah Jurnal Informasi dan komputer (JIK) STMIK Dian Cipta Cendikia Kotabumi ini dapat terwujud.Jurnal Informasi dan Komputer (JIK) yang terbit dua (2) kali dalam setahun ini merupakan suatu wadah untuk penyebar luasan hasil-hasil penelitian, studi pustaka, karya ilmiah yang berkaitan dengan Informasi dan Komputer khususnya bagi dosen-dosen STMIK Dian Cipta Cendikia Kotabumi serta umumnya para cendikiawan, praktisi, peneliti ilmu Informatika dan Komputer.

Harapan, dengan diterbitkannya Jurnal Informasi dan Komputer (JIK) ini sebagai salah satu bentuk sumbangan pemikiran dalam pengembangan ilmu informatika dan komputer yang berkaitan dengan kajian-kajian di bidang tekhnologi Informatik, Komunikasi Data dan Jaringan Komputer, perancangan dan Rekayasa Perangkat Lunak, serta ilmu-ilmu yang terkait dengan bidang Informasi dan Komputer lainnya.

Berkenaan dengan harapan tersebut, kepada para peneliti, dosen dan praktisi yang memiliki hasil-hasil penelitian, kajian pustaka, karya ilmiah dalam bidang tersebut diatas, dengan bangga redaksi Jurnal Informasi dan Komputer (JIK) menerima naskah ringkasan untuk dimuat pada jurnal Informasi dan Komputer (JIK) STMIK Dian Cipta Cendikia Kotabumi dengan berpedoman pada penulisan naskah jurnal sebagaimana dilampirkan pada halaman belakang (Bagian kulit dalam) buku jurnal ini.

Mutu dari suatu jurnal ilmiah tidak hanya ditentukan oleh para pengelolanya saja, tetapi para penulis dan pembaca jualah yang mempunyai peranan besar dalam meningkatkan mutu jurnal Informatika dan Komputer ini. Merujuk pada realita ini kamu sangat mengharapkan peran aktif dari peneliti untuk bersama-sama menjaga dan memelihara keberlangsungan dari jurnal Informasi dan Komputer STMIK Dian Cipta Cendikia Kotabumi ini. Yang juga tidak kalah pentingnya dari partisipasi tersebut diatas, adalah saran dan kritik yang membangun dari pembaca yang budiman agar kiranya dapat disampaikan langsung kepada redaksi JIK. Saran dan kritik yang membangun akan dijadikan masukan dan pertimbangan yang sangat berarti guna peningkatan mutu dan kualitas Jurnal Informasi dan Komputer STMIK Dian Cipta Cendikia Kotabumi.

Tak lupa diucapkan terima kasih yang tak terhingga atas perhatian dan kerjasama dari semua pihak yang tak dapat disebutkan satu persatu hingga dapat diterbitkan nya Jurnal Informasi dan Komputer (JIK) STMIK Dian Cipta Cendikia Kotabumi. Semoga apa yang telah diperbuat untuk kebaikan akan menjadi amal ibadah, amin.

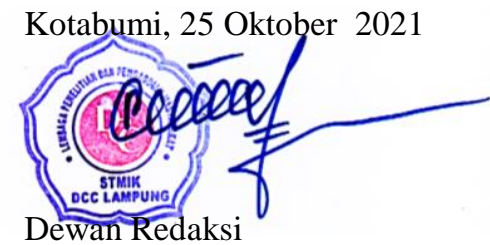




\section{JURNAL INFORMASI DAN KOMPUTER}

Volume 9 Nomor 2 Oktober 2021

Jurnal Informasi dan Komputer merupakan Sarana informasi ilmu pengetahuan, Tekhnologi dan Komunikasi yang berupa hasil penelitian, tulisan ilmiah, Ataupun studi pustaka. Jurnal ini terbit dua kali setahun pada bulan April dan Oktober. Berisi hasil penelitian ilmiah di bidang informatika yang bertujuan untuk menghubungkan adanya kesenjangan antar kemajuan teknologi dan hasil penelitian. Jurnal ini di terbitkan pertama kali pada tahun 2013.

Penanggung Jawab:

Ketua STMIK Dian Cipta Cendikia Kotabumi

\section{Pembina:}

Ketua STMIK Dian Cipta Cendikia Kotabumi Ketua Lembaga Penelitian STMIK Dian Cipta Cendikia Kotabumi

\section{Pimpinan Redaksi}

Dwi Marisa Efendi,.S.Kom.,M.Ti

\section{Redaksi pelaksana}

Rustam,.S.Kom,.M.Ti (STMIK Dian Cipta Cendikia Kotabumi)

Nurmayanti M.Kom (STMIK Dian Cipta Cendikia Kotabumi)

Sukatmi,.S.Kom., M.Kom (AMIK DCC Bandar Lampung)

Sampurna Dadi Riskiono,M.Kom (Universitas Teknokrat Indonesia)

Ifo Wahyu Pratama,S.Kom.,M.Ti(AMIK MASTER Lampung)

\section{Mitra Bestari}

Dr. RZ. ABDUL AZIZ, ST., MT (Institut Informatika dan Bisnis Darmajaya)

Dr. Dadang Sudrajat, S.Si, M.Kom (STMIK IKMI Cirebon)

Dr. Septafiansyah Dwi Putra, S.T., M.T (Politeknik Negeri Lampung)

Dr. Evi Grativiani, S.E., M.S.I (Universitas Sebelas Maret)

Rohmat Indra Borman ( Universitas Teknokrat Indonesia )

Ferry Wongso, S.KOm., M.Kom ( STMIK Darma Pala Riau)

Ferly Ardhy, S.Kom., M.Ti ( Universitas Aisyah Pringsewu )

Firmansyah, S.E., M.Si (STMIK Darma Pala Riau)
Amarudin (Universitas Teknokrat Indonesia)

Didi Susianto, S.T., M.Kom (AMIK Dian Cipta Cendika Bandar Lampung)

Alhibarsyah, St., M.Kom (STMIK Tunas

Bangsa Bandar Lampung)

Kemal Farouq Mauladi, S.Kom .M.Kom (Universitas Islam Lamongan)

Rima Mawarni, M.Kom ( STMIK Dian Cipta Cendikia Kotabumi)

Wira Jaya Hartono, S.Pd., M.Pd ( STMIK Darma Pala Riau)

Penerbit : STMIK Dian Cipta Cendikia Kotabumi Bekerja Sama Dengan LPPM STMIK Dian Cipta Cendikia Kotabumi.

\section{Alamat Redaksi/Penerbit:}

Jl. Negara No. 3 Candimas Kotabumi Lampung Utara

No Telpon/Fax 072423003

Email : 1ppm-stmik@dcc.ac.id 


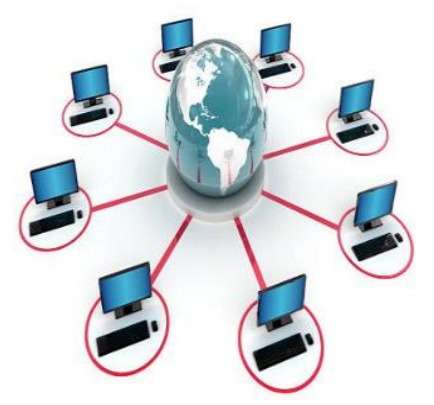

\section{JURNAL INFORMASI DAN KOMPUTER VOL. 9 NO. 2 THN. 2021}

\section{DAFTAR ISI}

\section{Halaman}

Sistem Informasi Akuntansi Persedian Barang Berbasis Web Pada Lembaga

Permasyarakatan Kelas II A Banceuy Bandung : "Kelompok Tani Desa Banjar Kertarahayu"

Teuku Rian Hardiyansyah, Fatia Salsa Azzahra

Ganesha Bandung ${ }^{1,2}$ )

(Politeknik Piksi 01-07

Penerapan Finite State Automata Pada Vending Machine Penjual Obat Non Resep Dokter Dan Keperluan Medis

Eko Supriyanto $^{1}$, Angga Ardiansyah ${ }^{2}$, Frieyadie $^{3}$, Sri Rahayu ${ }^{4}$, Windu Gata ${ }^{5}$

(Universitas Nusa Mandiri ${ }^{12}$ )

Sistem Pendukung Keputusan Untuk Menentukan Kelayakan Pengajuan Sertifikasi Guru Dengan Metode Simple Additive Weighting (Studi Kasus : Ma Al Muhajirin Janti Jogoroto Jombang)

Budiman, umam baharudin, winarti

(Universitas Darul 'Ulum Jombang)

Perancangan Infrastruktur Domain Name Server Lokal Menggunakan Ubuntu Server 16.04

Pada PT. Xyz

Zaenal Mutaqin Subekti, Hendra Setiawan, Satria, Widia Murni Wijaya,

Aliy Hafiz, Warsudi

(STMIK Bani Saleh, Universitas Negeri Yogyakarta, AMIK Dian Cipta Cendikia,

STMIK MIC CIkarang).

Perancangan Sistem Informasi Idea Proposal (Ip) Berbasis Web Pada Pt. Paxel Algorita Unggul

Julian Murhan Sahputra, Indah Purnamasari

(Universitas Nusa Mandiri ${ }^{12}$ )

Sistem Pendukung Keputusan Untuk Menentukan Ekstrakurikuler Atletik

Berdasarkan Bakat Siswa Menggunakan Metode Profile Matching

2.

Agnes Basuki,

Petrus Sokibi, Tiara Eka Putri

(Universitas Catur Insan Cendekia) $36-50$

Penerapan Algoritma K-Means Untuk Pengelompokan Usia Calon Penerima Vaksin

Di Kab. Ngawi

Irna Yuniarfi, Saifulloh

(Universitas PGRI Madiun ${ }^{12}$ ) $51-62$

System Penilaian Seleksi Calon Karyawan Baru Menggunakan Metode Simple Additive Weighting (SAW) Di PT.TNA

Anik Sri Wahyuningsih, Yudhi Firmansyah 
(Universitas Panca Sakti Bekasi ) $63-74$

Perancangan Sistem Informasi Pembayaran SPP Menggunakan Framework Laravel Ichwan Habib Moudi

(Universitas Panca Sakti Bekasi)

Implementasi Algoritma K-Means Dan Algoritma Apriori Optimasi Kinerja Ecu

(Study Kasus Mobil Avanza Dan Xenia)

Sigit Mintoro' Asep Afandi

3.

(STMIK Dian Cipta

Cendikia Kotabumi)

Sistem Pakar Penyakit Buah Kakao Untuk Peningkatan Hasil Panen Kakao Menggunakan

Metode Case Base Reasoning (CBR) Berbasis Web Mobile

Aliy hafiz, Verawati

(AMIK Dian Cipta Cendikia,Bandar Lampung)

Penerapan Metode Rapid Application Develomment (RAD) Dalam Pengembangan

Sistem Pemesanan Menu Berbasis Android

Aris Baihaqi, Tumini

(Fakultas Sains dan Teknologi ${ }^{1,2}$ )

Rancang Bangun Sistem Informasi Geografis Pariwisata Di Lampung Timur

Sukatmi, Rexa Alfa Rizi

(AMIK DCC Bandar Lampung ${ }^{12}$ )

Implementasi Psak No. 45 Pada Proses Penyusunan Laporan Keuangan Menggunakan

M.S. Excel Dan Aplikasi Accurate Accouting Pada STMIK Bani Saleh

Marhakim, Willy Adam

$\left(\right.$ STMIK Bani Saleh ${ }^{12}$ )

Sistem Prediksi Harga KOPI LAMBAR ( Lampung Barat) Dengan Metode

Backpropagation, dan Double Exponential ( Studi Kasus BUMDES )

Supriyanto, Dwi marisa Efendi,Rhomadhon

(STMIK Dian Cipta cendikia Kotabumi ${ }^{1-}$ )

Sistem Informasi Pemasaran Produk Umkm Berbasis Web Pada Kecamatan Bumi

Nabung Lampung Tengah

Yuli Syafitri, Agus Prasetyo, Reni Astika

(AMIK Dian Cipta Cendikia Bandar Lampung)

Rancang Bangun Aplikasi Pembelajaran Aksara Lampung Berbasis Android

Ferly Ardhy, Hendra Syahrobi

(Universitas Aisyah Pringewu ${ }^{1,}$ STMIK Dian Cipta Cendikia ${ }^{2}$ )

Sistem Pakar Diagnosa Penyakit Kulit Pada Balita Menggunakan Metode Naïve

Bayes Dan Forward Chaining Studi Kasus Puskesmas Cempaka Sungkai Selatan

Sidik Rahmatullah, Rima Mawarni

(STMIK Dian Cipta Cendikia Kotabumi ${ }^{12}$ )

Rekayasa Perangkat Lunak Perhitungan Harga Pokok Produksi Metode

Full Costing Pada Umkm Mitra Cake Di Bandar Lampung

Pitrawati, Arif Sanjaya

(AMIK Dian Cipta Cendikia, Bandar Lampung) 
Rancang Bangun Sistem Ujian Online Menggunakan Algoritma Cosine Similarity

Berbasis Web

Haryono, Zaenal Mutaqin Subekti, Widiyawati, Hidayatullah

(STMIK Bani Saleh ${ }^{1234}$ )

Model Aplikasi Helpdesk Ticketing System Berbasis Web Menggunakan Metode Rad Indra Permana

Pattern Recognition Tulisan Tangan Huruf Hijaiyah Menggunakan Metode

Convolutional Neural Network (CNN)

Mufassiril Abror, Nopiyanto

(Universitas Panca Sakti Bekasi ${ }^{12}$ )

Aplikasi Sistem Informasi Keuangan Berbasis Android Di Perumahan Taman

Karang Bahagia

Melda Ayulestari

(Universitas Panca Sakti Bekasi)

Audit Pelayanan Sistem Rujukan Online Puskesmas Menggunakan Framework COBIT 5.0

Nurmayanti, Merri Parida, Ngajiyanto, Ina Anzalna

(STMIK Dian Cipta Cendikia Kotabumi ${ }^{1234}$ )

Perancangan Sistem Informasi Pengolahan Data Nilai Siswa Berbasis Web

Erin Ermawati, Anik Sri Wahyuningsih

(Fakultas Sain dan Teknologi, Universitas Panca Sakti Bekasi ${ }^{12}$ )

Pengembangan Sistem Pelaporan Data Hasil Inspeksi Barang Berbasis Web

Siska Putriani

(Universitas Pancasakti Bekasi)

Penerapan Extreme Programming Dalam Perancangan Aplikasi Web Food Market

Tumini, Hilman Septiana

(Fakultas Sains dan Teknologi Universitas Panca Sakti Bekasi ${ }^{1,2}$ )

Sistem Pencarian Barang Berbasis Website Menggunakan Php Dan Mysql

Studi Kasus PT. Surya Technology Industri Sulaeman

(Universitas Panca Sakti Bekasi)

Implementasi Metode Prototype Pada Sistem Peminjaman Alat Kerja Berbasis Web

Di PT SK Metalindo

Ali Mulyanto, Arjun Gunawan

(Univeritas Panca Sakti Bekasi)

Aplikasi Tata Cara Wudhu Menggunakan Teknologi Augmented Reality

Sebagai Media Pembelajaran Di TK Al Fatih

Ahmad Yakub , Idarul Fadli

(Universitas Panca Sakti Bekasi ${ }^{12}$ )

Sistem Pakar Diagnosa Penyakit Ayam Petelur Menggunakan Metode Certainty Factor

Berbasis Web Mochammad

Taufiq Hidayat, Ali Mulyanto

(Universitas Panca Sakti Bekasi ${ }^{12}$ ) 
Penerapan Metode Prototyping Dalam Perhitungan Hasil Produksi Menggunakan

Arduino Uno R3 Dan Php Di PT. Indonesia Epson Industry

Amandha Aulia, Ajar Rohmanu

(Universitas Panca Sakti Bekasi ${ }^{12}$ )

System Pendukung Keputusan Penentuan Guru Teladan Dengan Metode Profile Matching

Hasbulloh, Agmawarnida

(Universitas Panca Sakti Bekasi ${ }^{1,2}$ )

Implementasi Waterfall Method Pada Aplikasi Buku Induk Siswa Berbasis Web

Idam Holid, Yogie Krisnayadi

(Universitas Panca Sakti ${ }^{12}$ )

Pengembangan Text To Speech Media Pembelajaran Untuk Pengenalan

Anggota Tubuh Manusia Kelas V Sekolah Dasar

Juwanda Saputra, Ali Mulianto

(Teknik Infomratika Fakulutas Sains dan Teknologi ${ }^{12}$ )

Perancangan Sistem Peminjaman Barang Berupa Aset Tetap Berbasis Web

Pada Lembaga Permasyarakatan Kelas II A Banceuy Bandung

Guntur Salasa Priambodo, Perwito, Candra Mecca Sufyana

(Politeknik Piksi Ganesha Bandung ${ }^{1,2,3}$ )

Metode Pemilihan Karyawan Terbaik Sebagai Penentu Goodwill Perguruan Tinggi

Dengan Menggunakan Metode Topsis (Studi Kasus Perguruan Tinggi Di Lampung Utara)

Dwi Sartika, Pakarti Riswanto

(STMIK Dian Cipta Cendikia Kotabumi)

Sistem Pendukung Keputusan Pemilihan Merek Smartphone Menggunakan

Metode Analytical Hierarchy Process (AHP)

Ade Kiki Fatmawati, Muhammad Sultan Raflie, Norma Yunita

(Universitas Nusa Mandiri ${ }^{123}$ )

Pattern Recognition Aksara Lampung Menggunakan Algoritma Neural Network

Metode Analytical Hierarchy Process (AHP)

Nopiyanto, Rahmadi

(Universitas Panca Sakti Bekasi) 


\title{
PENGEMBANGAN TEXT TO SPEECH MEDIA PEMBELAJARAN UNTUK PENGENALAN ANGGOTA TUBUH MANUSIA KELAS V SEKOLAH DASAR
}

\author{
Juwanda Saputra ${ }^{1}$, Ali Mulianto ${ }^{2}$ \\ Teknik Infomratika Fakulutas Sains dan Teknologi ${ }^{12}$ \\ juwandasyahputra@gmail.com alimulyanto.psub@gmail.com
}

\begin{abstract}
ABSTRAK
Metode belajar secara konvensional dengan mendengarkan penjelasan dari guru sangat membosankan untuk para murid. Sehingga ketika guru memberikan materi, mereka sering tidak memperhatikan. Bahkan ketika berada di rumah, tidak jarang sulit sekali untuk mengajak mereka untuk belajar sendiri atau sekedar mengulangi pelajaran yang telah diterima di sekolah terlebih lagi mereka berada pada usia yang suka bermain. Jadi mereka harus dimanjakan atau dipancing dengan hal-hal yang mereka sukai ketika belajar. Contohnya seperti menyediakan gambar-gambar, video dan suara untuk gambar materi yang lebih menarik Hal yang dilakukan penulis membangun Pengembangan Text to Speach tentang pengenalan Pengenalan Organ Tubuh yang dibangun menggunakan Digital Human. Dalam media pembelajaran ini, materi disampaikan dengan suara, gambar 3 dimensi dan vidwo yang menarik untuk menambah minat para murid untuk belajar.
\end{abstract}

Kata kunci: Pembelajaran,Anak SD, Pengenalan Tubuh, Digital Human

\section{ABSTRACT}

The conventional learning method by listening to the teacher's explanation is very boring for the students. So when the teacher gives the material, they often do not pay attention. Even when they are at home, it is not infrequently difficult to invite them to study on their own or just to repeat the lessons that have been received at school, especially when they are at an age who likes to play. So, they should be pampered or provoked with the things they enjoy while studying. For example, providing pictures, videos and sounds for more interesting material images. What the author did was to build the Development of Text to Speech about the introduction of Body Organ Recognition which was built using Digital Human. In this learning media, the material is delivered with sound, 3-dimensional images and interesting videos to increase students' interest in learning.

Keywords: Learning, Elementary School Children, Body Recognition, Digital Human

\section{PENDAHULUAN}

\subsection{Latar Belakang Maslah}

Tubuh manusia merupakan salah satu bidang keilmuan medis yang mempelajari struktur tubuh manusia. Sebagai manusia, kita sangat diperlukan untuk mengenal anatomi tubuh diri kita sendiri. Sebab, dengan mengenal dan memahami setiap bagian tubuh kita, kita bisa tahu pola hidup sehat dan lebih peduli dalam menjaga kesehatan tubuh. Sehingga penting sekali untuk kita khususnya anak-anak memahami bagian penting dari tubuhnya sendiri agar selalu menjaga organ-organ penting dapat berfungsi dengan baik..
Pada siswa kelas V SD sudah belajar tentang organ- organ tubuh manusia atau anatomi tubuh manusia. Namun sistem pembelajaran yang ada di SD tersebut masih menggunakan cara yang konvensional yaitu menggunakan buku. Tetapi buku yang digunakan masih bersifat 2D (dua dimensi), penuh dengan teks, gambar kurang jelas dan kurang interaktif. Sehingga media tersebut belum mampu menjadi media pengenalan anatomi tubuh manusia yang menarik untuk siswa kelas V SD. Menurut pihak sekolah sendiri siswa terkadang tidak terlalu dapat memahami materi yang diberikan jika hanya mengandalkan media buku saja, 
hal ini dapat berakibat kejenuhan dan siswa menjadi malas dalam memahami materi.

Aplikasi pengenalan anatomi tubuh manusia ini mengedepankan teknologi 3 (tiga) dimensi, materi video, Text to Speach karena dengan menggunakan teknologi ini dapat memungkinkan pengguna melihat objek anatomi tubuh manusia secara lebih nyata dengan memproyeksikan objek dalam bentuk $3 D$ (tiga dimensi). Penggunaan teknologi ini juga dapat menambah nilai dari penyampaian informasi menjadi lebih tinggi. Teknik yang penulis sampaikan dapat memperluas lingkungan dunia nyata dengan beberapa objek virtual yang muncul dalam pandangan user. Teknologi ini akan digabungkan ke dalam suatu aplikasi untuk mengenalkan anatomi tubuh manusia secara lebih nyata untuk menghasilkan aplikasi yang lebih menarik dalam pengenalan anatomi tubuh manusia bagi siswa kelas V SD. Aplikasi ini berbasiskan desktop dan mobile, karena di SD sudah tersedia fasilitas laboratorium khusus komputer sehingga pengguna dapat mempelajari materi dengan baik. Aplikasi ini menggunakan metode markerless karena marker yang digunakan adalah sebuah gambar anatomi tubuh manusia sesuai dengan kurikulum materi yang diberikan. Aplikasi juga mengimplementasikan TTS (Text To Speach) Interaction, yang diharapkan dapat menambah interaksi antara pengguna dengan aplikasi serta menerapkan suara sebagai pendukungnya. Didalam aplikasi ini dapat menampilkan animasi anatomi dalam bentuk $3 D$ dan terdapat penjelasan tentang anatomi tubuh manusia. Dalam pembangunan aplikasi ini diharapkan dapat menjadi solusi bagi guru yang mengajar untuk memberikan suatu pengetahuan tentang organ penting yang ada dalam tubuh manusia kepada siswa dengan lebih baik.

\section{METODE PENELITIAN}

Penelitian ini digambarkan menggunakan diagram alur atau flow chart, ini akan menggambarkan alur proses atau tahapantahapan penelitian mulai dari awal sampai selesai. Diagram alir digunakan untuk memudahkan pembaca untuk memahami metode penelitian yang dilakukan. Secara lengkap tahapan penelitian dapat dilihat pada gambar
Tujuan dari penelitian ini adalah membuat aplikasi media pembelajaran di SDN Karang Asih 14 menggunakan teknologi Augmented Reality, 3D, TTS dan HumAn Body yang dapat di implementasikan pada sekolah.

Bagi Peneliti, Penelitian ini dapat menambah pengetahuan peneliti dan dapat lebih mengetahui factor-faktor yang mempengaruhi pembelajaran di SDN Karang Asih 14.

Bagi Peneliti selanjutnya, hasil dari penelitian ini diharapkan dapat digunakan sebagai tambahan referensi dalam penelitian berikutnya. Bagi Pengguna sistem, hasil dari penelitian ini diharapkan dapat menjadi bahan acuan agar dapat meningkatkan efektivitas dan efisiensi dalam pembelajaran siswa. Bagi Sekolah, hasil dari penelitian ini diharapkan dapat menjadi masukan dan pertimbangan agar Sekolah dapat menyajikan aplikasi Bagi IPTEK. hasil dari penelitian ini diharapkan dapat menjadi masukan dan pertimbangan ketika merancang sebuah sistem aplikasi media pembelajaran Pengenalan Tubuh dengan menggunakan Teknologi TTS, 3D dan Video.

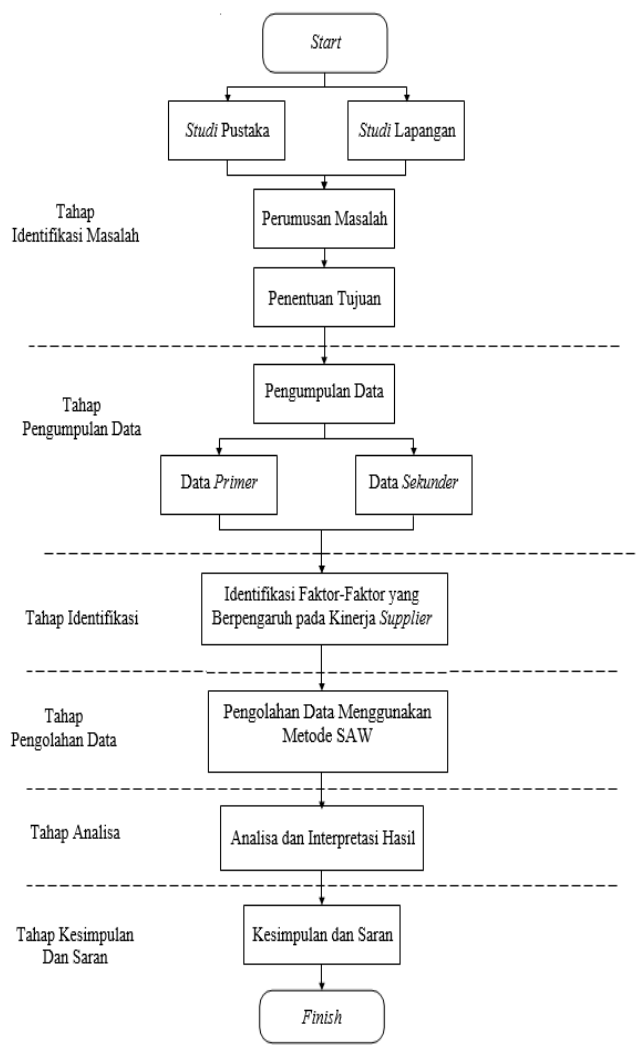




\section{HASIL DAN PEMBAHASAN}

\subsection{Hasil}

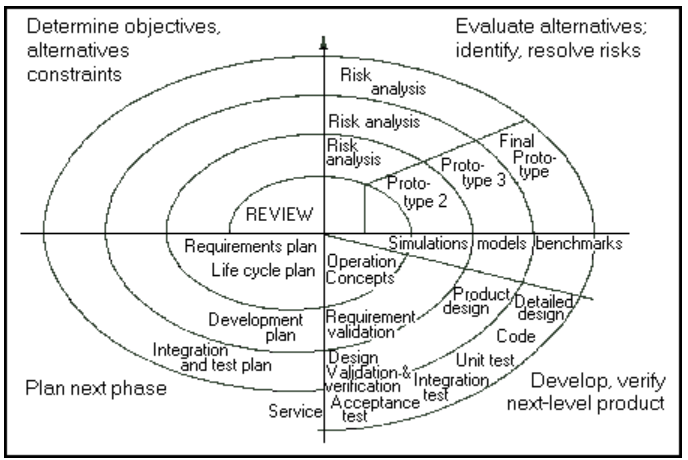

Pada tahapan ini diperlukan komunikasi yang bertujuan untuk memperoleh informasi tentang perangkat lunak yang diharapkan oleh pengguna. Informasi ini diharapkan dapat menjadi acuan dan batasan untuk pengembangan perangkat lunak yang akan dikembangkan. Informasi ini diperoleh dengan wawancara, studi literatur dan survei langsung. Kemudian informasi yang didapatkan dianalisis untuk memperoleh data yang dibutuhkan oleh pengguna.

Penulis menggunakan metode spiral dalam menyelesaikan Tugas akhir ini, permodelan ini penulis gunakan karena model ini juga mengkombinasikan top-down design dengan bottom-up design, dimana top-down design menetapkan sistem global terlebih dahulu, baru diteruskan dengan detail sistemnya, sedangkan bottom-up design berlaku sebaliknya. Top-down design biasanya diaplikasikan pada model waterfall dengan sequential-nya, sedangkan bottom-up design biasanya diaplikasikan pada model prototyping dengan feedback yang diperoleh. Dari 2 kombinasi tersebut, yaitu kombinasi antara desain dan prototyping, serta top-down dan bottom-up, yang juga diaplikasikan pada model waterfall dan prototype, maka spiral model ini dapat dikatakan sebagai model proses hasil kombinasi dari kedua model tersebut. Oleh karena itu, model ini biasanya dipakai untuk pembuatan software dengan skala besar dan kompleks. Satu lingkaran dari bentuk spiral pada spiral model dibagi menjadi beberapa daerah yang disebut dengan region. Region tersebut dibagi sesuai dengan jumlah aktivitas yang dilakukan dalam spiral model. Tentunya lingkup tugas untuk project yang kecil dan besar berbeda. Untuk project yang besar, setiap region berisi sejumlah tugas-tugas yang tentunya lebih banyak dan kompleks daripada untuk project yang kecil. SE berjalan dari inti spiral berjalan mengitari sirkuit per sirkuit. Sebagai contoh untuk sirkuit pertama dilakukan untuk pembangunan dari spesifikasi dari software dengan mencari kebutuhan dari customer. Untuk sirkuit pertama harus menjalani semua aktivitas yang didefinisikan. Setelah 1 sirkuit terlewati lanjut ke tugas selanjutnya misalnya membangun prototype. Tugas ini juga harus mengitari 1 sirkuit dan begitu terus selanjutnya sampai project selesai. Tidak seperti model-model konvesional dimana setelah SE selesai, maka model tersebut juga dianggap selesai. Akan tetapi hal ini tidak berlaku untuk spiral model, dimana model ini dapat digunakan kembali sepanjang umur dari software tersebut. Pada umumnya, spiral model digunakan untuk beberapa project seperti Concept Development Project (proyek pengembangan konsep), New Product Development Project (proyek pengembangan produk baru), Product Enhancement Project (proyek peningkatan produk), dan Product Maintenance Project (proyek pemeliharaan proyek). Keempat project tersebut berjalan berurutan mengitari sirkuit dari spiral. Sebagai contoh setelah suatu konsep dikembangkan dengan melalui aktivitasaktiviats dari spiral model, maka dilanjutkan dengan proyek selanjutnya yaitu pengembangan produk baru, peningkatan produk, sampai pemeliharaan proyek. Semuanya melalui sirkuit2 dari spiral model.

Penulis menggunakan permodelan Spiral karena Pendekatan dengan model ini sangat baik digunakan untuk pengembangan sistem software dengan skala besar maupun skala kecil, Karena progres perkembangan dari SE dapat dipantau oleh kedua belah pihak baik developer maupun user / customer, sehingga mereka dapat mengerti dengan baik mengenai software ini begitu juga dengan resiko yang mungkin didapat pada setiap aktivitas yang dilakukan. Selain dari kombinasi 2 buah model yaitu waterfall dan prototyping, kelebihan dari software ini ada pada analisis resiko yang dilakukan, sehingga resiko tersebut dapat direduksi sebelum menjadi suatu masalah besar yang dapat menghambat SE. Model ini membutuhkan konsiderasi langsung terhadap resiko teknis, sehingga diharapkan dapat 
mengurangi terjadinya resiko yang lebih besar. Sebenarnya dengan menggunakan prototype juga bisa menghindari terjadinya resiko yang muncul, tetapi kelebihan dari model ini yaitu dilakukannya proses prototyping untuk setiap tahap dari evolusi produk secara kontinu. Model ini melakukan tahap2 yang sudah sangat baik didefinisikan pada model waterfall dan ditambah dengan iterasi yang menyebabkan model ini lebih realistis untuk merefleksikan dunia nyata. Hal-hal itulah yang menjadi kelebihan menggunakan spiral model.

\subsection{Pembahasan}

Dapat dilihat blok diagram dan flowchart alur sistem dalam perancang aplikasi Text To speech pengucapan suara dalam pengenalan tubuh dapat dilihat pada gambar:

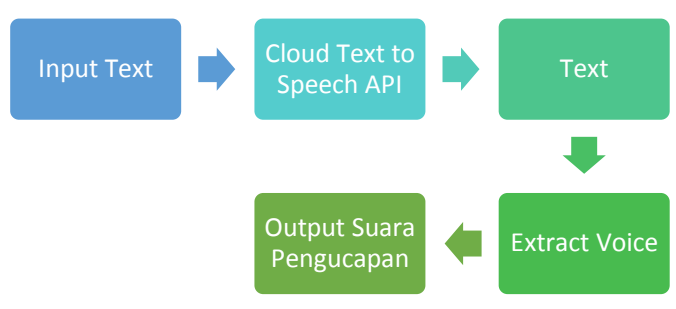

Gambar 1 Proses Text To Speech

Sistem aplikasi text to speech ini melalui proses memasukkan citra karakter yang ingin dikenali ke sistem. Dalam aplikasi sebelumnya sudah diinput kalimat dalam bahasa Inggris, Setelah text diketik tahap selanjutnya melakukan konversi dari teks ke suara dengan bantuan cloud Text to speech API untuk menghasilkan suara pengucapan kata. Alur sistem dalam perancangan Aplikasi Text To Speech dalam pengenalan tubuh akan di ucapkan dalam bahasa inggris, dalam proesi ini adalah adalah merubah teks hasil pengenalan menjadi suara pengucapan kata dalam bahasa Inggris. dengan membandingkan srting text inputan dengan Cloud Text To Speech API yang dimiliki oleh Google Developer, setelah itu Ekstrak suara terlebih dahulu dan pilih suara yang ada tersedia di perpustakaan Cloud Text To Speech API serta Menginisialisasi wave player untuk mengubah teks menjadi suara yang diinginkan. Untuk lebih jelasnya alur sistem perancangan aplikasi text to speech dipresentasikan oleh use case diagram dan activity diagram.

\subsection{Use Case Diagram}

Pada Use Case Diagram kebutuhan fungsional pengguna meliputi input text kedalam program akan medeteksi bahasa yang dipergunakan teks bahasa Inggris dan mengubahnya ke suara pengucapam dalam bahasa Inggris, yang akan menghasilkan output berupa suara dalam bahasa inggris.

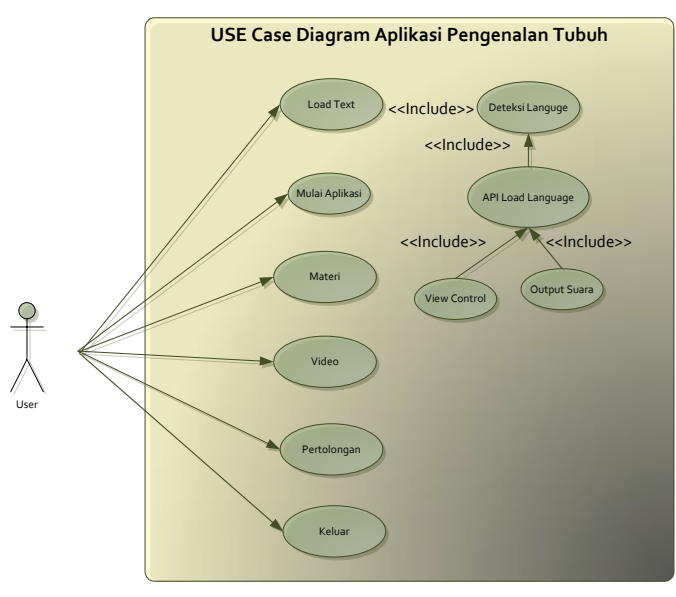

Gambar 2 Use Case Diagram

Skenario pada menu mulai Aplikasi diawali dengan pengguna membuka aplikasi dan masuk pada menu utama. Kemudian pada menu utama terdapat lima menu yaitu mulai materi, bantuan, video, detail dan keluar. Kemudian pengguna masuk pada menu mulai menu utama. Pengguna memilih menupada aplikasi objek 3D ditampilkan disertai dengan view control berupa tombol zoom in, zoom out, rotate left, rotate right. Kemudian pengguna menekan tombol deskripsi untuk menampilkan deskripsi dari objek. Skenario use case mulai aplikasi dapat dilihat pada Tabel 1 .

Tabel 1 Skenario Aplikasi

\begin{tabular}{|l|l|}
\hline Nama Use Case & Mulai AR \\
\hline Aktor & User \\
\hline Tujuan & $\begin{array}{l}\text { User memilih menu } \\
\text { Mulai APlikasi dan } \\
\text { berhasil menampilkan } \\
\text { objek 3D beserta view } \\
\text { control }\end{array}$ \\
\hline Keadaan awal & $\begin{array}{l}\text { Aplikasi menampilkan } \\
\text { menu utama }\end{array}$ \\
\hline
\end{tabular}




\begin{tabular}{|c|c|}
\hline \multicolumn{2}{|l|}{ Skenario } \\
\hline Aksi Aktor & Reaksi Sistem \\
\hline \multirow[t]{2}{*}{$\begin{array}{l}\text { 1. Memilih menu } \\
\text { Mulai Aplikasi }\end{array}$} & \\
\hline & $\begin{array}{l}\text { 2. Menjalankan } \\
\text { Aplikasi }\end{array}$ \\
\hline \multirow{3}{*}{ 3.Menunjukan Text } & \\
\hline & $\begin{array}{l}\text { 4. Menditeksi } \\
\text { languagge }\end{array}$ \\
\hline & $\begin{array}{l}\text { 5. Memuat view } \\
\text { control berupa tombol } \\
\text { zoom in, zoom out, } \\
\text { rotate left, rotate right }\end{array}$ \\
\hline \multirow[t]{2}{*}{$\begin{array}{l}\text { 6. Menekan tombol } \\
\text { deskripsi }\end{array}$} & \\
\hline & $\begin{array}{l}\text { 7. Menampilkan } \\
\text { deskripsi objek }\end{array}$ \\
\hline \multirow[t]{2}{*}{$\begin{array}{l}\text { 8. Menekan tombol } \\
\text { suara }\end{array}$} & \\
\hline & $\begin{array}{l}\text { 9. Mengeluarkan } \\
\text { Output Suara }\end{array}$ \\
\hline
\end{tabular}

\subsection{Activity Diagram}

Activity diagram yang dibuat menggambarkan aktifitas yang terjadi pada aplikasi pengenalan anatomi tubuh manusia berbasis text to speech. Aktifitas dari program dijalankan hingga program diakhiri. Aktifitas pertama yaitu pengguna membuka aplikasi dan masuk pada menu utama. Pada menu utama terdapat empat menu di antaranya yaitu menu mulai video, materi, bantuan, dan keluar. Pada menu mulai aplikasi pengguna akan dibawa pada menu utama yang akan membuka halaman utama. Apabila user memilih menu pengenalan tubuh dan memilih salah satu menu, maka sistem akan mengeluarkan ouput berupa gambar 3 Dimensi dan deskripsi, kemudian akan mengeluarkan output berupa suara tombol deskripsi ditekan. Pada menu materi terdapat aktifitas membuka form materi yang berisikan informasi mengenai mengenai anatomi tubuh manusia. Dan pada menu bantuan terdapat aktifitas membuka form bantuan yang berisikan informasi mengenai cara penggunaan daripada aplikasi pengenalan anatomi tubuh manusia berbasis teknologi augmented reality. Activity diagram aplikasi pengenalan anatomi tubuh manusia dapat dilihat pada gambar.

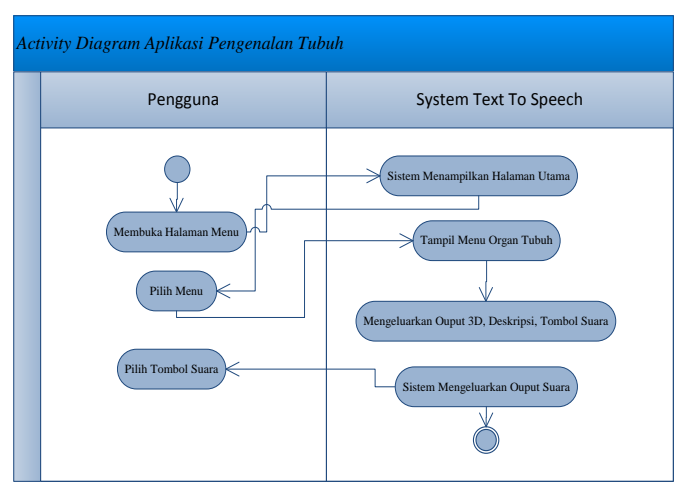

Gambar 3 Activityu Diagram

\subsection{Menu Utama}

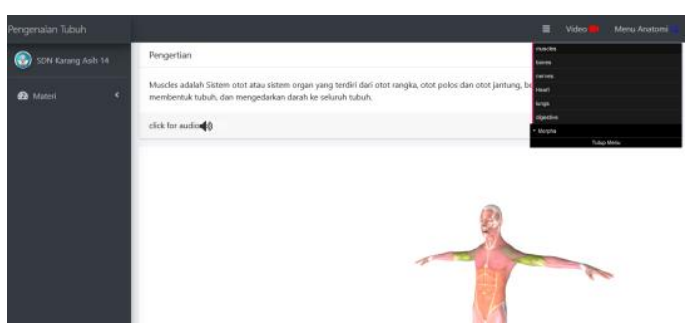

Gambar 4 Menu Utama

\subsection{Menu Materi}

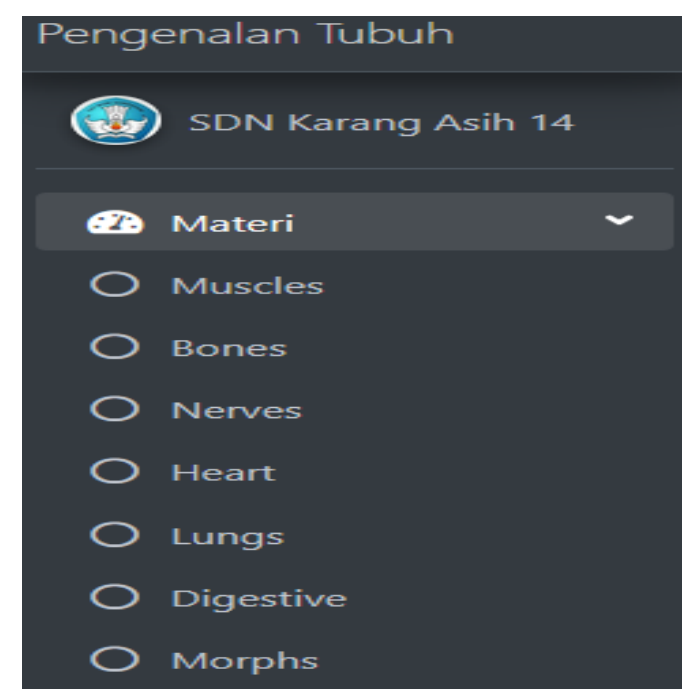

Gambar 5 Menu Materi 


\subsection{Menu Video}

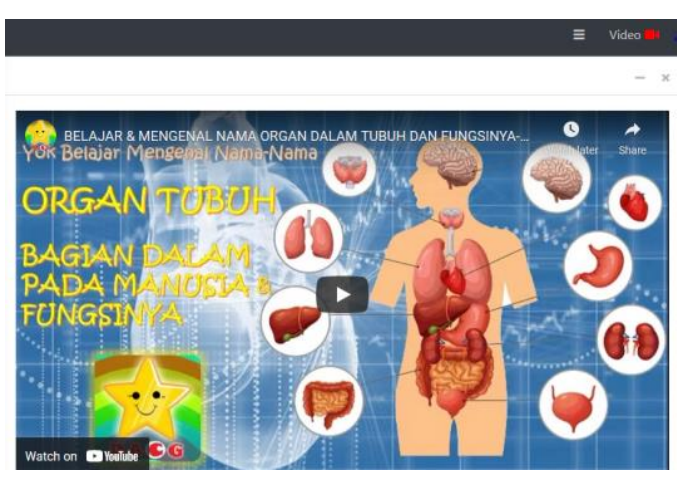

Gambar 6 Menu Video

\subsection{Gambar 3 Dimensi}

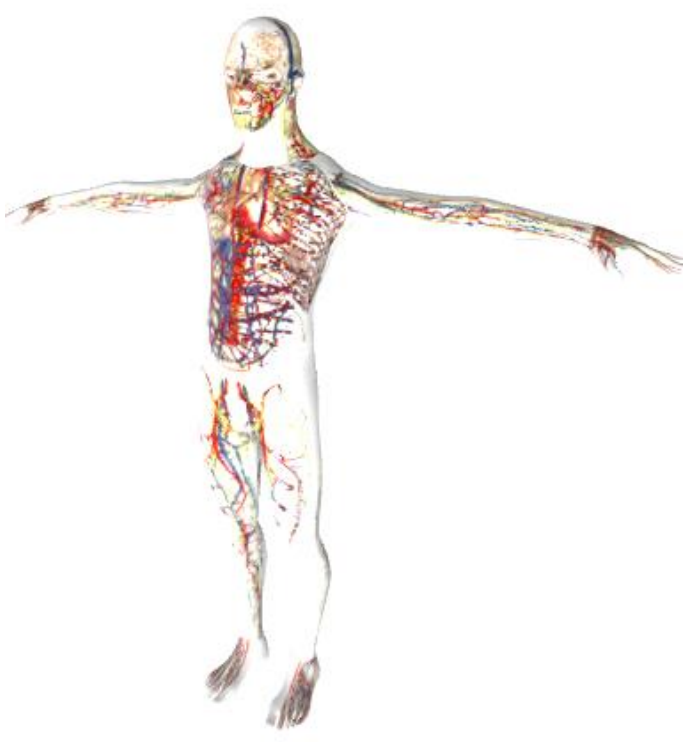

Gambar 7 Gambar 3 dimensi

\section{KESIMPULAN DAN SARAN}

\subsection{Kesimpulan}

Berdasarkan hasil penelitian dan pembahasan maka penelitian ini dapat mengambil kesimpulan sebagai berikut

1. Penelitian ini menghasilkan Aplikasi Pengenlan Tubuh untuk siswa kelas V Sekolah Dasar

2. Pengelan Tubuh menghasilkan Aplikasi Text To Speech dalam pengucapan kata dalam bahasa Inggris berbasis android yang menggunakan inputan atau masukan berupa text yang disimpan pada program aplikasi yang akan dikenali ke teks dan mengeluarkan suara pengucapan dalam bahasa Inggris dengan pengkonversi kata ke suara menggunakan Cloud Text to Speech API serta ditambahkan Cloud Google Translate API

\subsection{Saran}

Berdasarkan dari simpulan dan temuan dari penelitian yang telah dilakukan pada sistem, aplikasi yang dibangun masih memiliki beberapa kekurangan, oleh karena itu perlu adanya pengembangan agar sistem ini menjadi lebih baik, maka penelitian ini memberikan saran sebagai berikut :

1. Penambahan fitur-fitur lain yang lebih menarik seperti, menu translate sehingga dapat melakukan transleting langsung dari aplikasi.

2. Sistem dapat berjalan tanpa harus menggunakan koneksi internet atau offline yang akan lebih mempermudah pengguna yang tidak memiliki koneksi internet atau pengguna yang berada di suatu lokasi yang sulit terjangkau dengan koneksi internetTahapan selanjutnya adalah implementasi yang merupakan tahapa pengkodean hasil dari analisa dan perancangan ke dalam sistem, sehingga akan diketahui apakah sistem yang dibuat telah menghasilkan tujuan yang diinginkan. Rancangan sistem aplikasi Pengenalan Tubuh.

\section{DAFTAR PUSTAKA}

[1] Dutoit, Thierry.2021. "An Introduction To Text-To-Speech Synthesis", Dordrecht: Kluwer Academic Publisher.

[2] Http://Www.Microsoft.Com

[3]Parsons, Thomas W.1986. "Voice And Speech Processing", New York: Mcgraw-Hill.

[4] Pelton, Gordon E.1993. "Voice

Processing", New York:
Mcgraw-Hill.


[5] Efrizal, Jaroji, Agus Tedyyana Politeknik Negeri Bengkalis - Bengkalis. (2015). Jurnal Inovtek Polbeng Seri Informatika, Vol. 2, No. 2 , November 2017 ISSN : 25279866.

[6] JNTETI, Vol. 5, No. 1, Februari 2016, Pengembangan Aplikasi TextTo-Speech Bahasa Indonesia Menggunakan Metode Finite State Automata Berbasis Android

[7] Feby Zulham Adami, Cahyani Budihartanti- Jurnal Teknik Komputer Amik Bsvol. Ii No.1 Februari 2016; Issn 2442-2436 Penerapan Teknologi Augmented 122 Penerapan Teknologi Augmented Reality Pada Media Pembelajaran Sistem Pencernaan Berbasis Android. 